\title{
Dynamic Measurement of Four-Axle Railway Wagon
}

Martin Svoboda, Josef Soukup

Faculty of production technology and management of Jan Evangelista Purkyně University in Ústí nad Labem, Na Okraji 1001, Czech Republic. E-mail: svoboda@fvtm.ujep.cz

This article describes the determination of geometric, mass and stiffness parameters of the individual part of plateau wagon. After measurements were taken the position change of the chassis of the vehicle body and wheel when driving the vehicle over obstacles was observed. The obstacles were formed by wedges. Experimental detection of parameter has been used in the analytical investigation of kinematically excited system of three-body space flexibly stored and linked.

Keywords: railway vehicles, dynamic measurements, vertical oscillation, unbalance

\section{Acknowledgement}

This article was supported by Student Grant Competition of J. E. Purkyně University in Ústínad Labem.

\section{References}

[1] BREPTA, R., PŮST, L., TUREK, F.: Mechanické kmitání. Technický průvodce 71. Sobotáles, Praha 1994

[2] JANOUŠEK, P.: Technická zpráva - tz 040/2007. Praha 2007

[3] BLUNDELL, M., HARTY, D.: The multibody systems approach to vehicle dynamics. elsevier, 2004, ISBN 0750651121

[4] CHALUPA M.: Combined Metod of Driving System Dynamic Properties Analysis. In magazine "Machinebuilding \& Electrotechnic". Sofia 2005, ISNN 0025-455X

[5] CHALUPA M., KRATOCHVÍL C. A KOL.: Computer Metod of Analysis of Driving System Dynamic Properties. IN: "AT \& P JURNAL PLUS". Bratislava: HMH S.R.O. Tavarikova Osada 39, 84102 Bratislava 42, 2007, ISNN $1336-5010$

[6] HARUŠINEC J., GERLICI J., LACK T.. Výpočet kontaktního napätia medzi železničním kolesom a kol'ajnicou ротосои MKP, In: Výpočtové a experimentální metody v aplikované mechanice, p. 107-118, Ústí nad labem, 2012, ISBN 978-80-7414-377-9

[7] WEINFURTNER L., PEXA M., MAYER K.: Stanovení životnosti ložisek na vibrodiagnostickém modelu., In: Strojírenská technologie, p. 52-59, Ústí nad Labem, 2011, ISSN 1211-4162

[8] VRKOSLAVOVÁ L., KRACÍK V.: Aplikace statistické metody ke zpracování naměřených da, In: Strojírenská technologie, p. 48-52, Ústí nad Labem, 2011, ISSN 1211-4162

[9] NOVÁK P., MEŠKO J., ŽMINDÁK M.: Finite Element Implementation of Multi-Pass Fillet Weld with Phase Changes, In: Manufacturing Technology, Volume 13, p. 79-85, Ústí nad Labem, 2013, ISSN 1213-2489

[10] KOVANDA K., HOLUB L., KOLAŘÍK L., KOLAŘÍKOVÁ M., VONDROUŠ M.: Experimental Verification of FEM Simulation of GMAW Bead on Plate Welding., In: Manufacturing Technology, Volume 12, p. 30-33, Ústí nad Labem, 2012, ISSN 1213-2489 